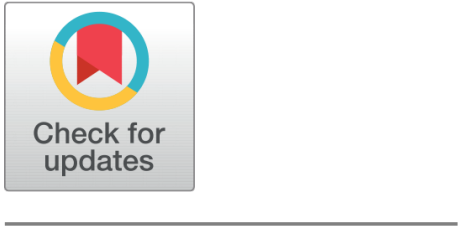

open acCess

Received: 09.05.2021

Accepted: 22.05.2021

Published: 13.06 .2021

Citation: Priya GS, Rajini A (2021) A Study on Mathematical characteristics in Indian Carnatic Musicians. Indian Journal of Science and Technology 14(21): 1711-1717. https://doi.org/

10.17485/IJST/v14i21.803

* Corresponding author.

spriya.mat@gmail.com

Funding: None

Competing Interests: None

Copyright: (c) 2021 Priya \& Rajini. This is an open access article distributed under the terms of the Creative Commons Attribution License, which permits unrestricted use, distribution, and reproduction in any medium, provided the original author and source are credited.

Published By Indian Society for Education and Environment (iSee)

ISSN

Print: 0974-6846

Electronic: 0974-5645

\section{A Study on Mathematical characteristics in Indian Carnatic Musicians}

\author{
G Santhi Priya1* A Rajini, ${ }^{1,2}$ \\ 1 Assistant Professor, Department of Mathematics and Statistics, Bhavan's Vivekananda \\ College of Science, Humanities and Commerce, Sainikpuri, 500094, Secunderabad, India \\ 2 Research Scholar, Department of Statistics, Osmania University, Hyderabad, 500007, India
}

\section{Abstract}

Background/Objectives: The main aim of this research is to observe the mathematical skills in Indian Carnatic musicians. Math and Music seem to be completely different fields of study, but there are a few similar cognitive abilities needed to learn mathematics as well as music. Any mathematical theory works on given premises, set of rules, assumptions and given constraints. The same way "Music" in-particular Indian Carnatic Music also needs a methodic way to learn and perform. Mathematics if rightly viewed not only possesses the truth but also beauty like music. Being good in one of them may enhance abilities in the other. Methods and Statistical Analysis: The data is collected from a sample of 153 respondents which is collected through a structured questionnaire using Microsoft forms based on random sampling method. The data have been analysed and hypotheses have been tested by using valid statistical tools that is descriptive statistics, chi square test using IBM SPSS version 25. Findings: Most of the hypotheses developed in this study were positively confirmed. This study observes the aptitude of the Carnatic musicians to be associated with mathematics up to considerable level of their education. It also reveals the impact of mathematics in understanding the observational skills to identify "Sruthi" one of the basic concepts Carnatic Music. Novelty: All the stake holders of Education can observe that learning of mathematics is not just as only practicing the high -level concepts but also to develop the logical and reasoning skills which are really needed for the excellence in other art forms like Music. Also, these types of quantitative measures can be used to scale the learning quality of any musician since excellence in Carnatic music may not be considered only by performance.

Keywords: Mathematical skills; Indian Carnatic Music; Sruthi; Rhythm

\section{Introduction}

Mathematics is one of the basic needs for human brain to enhance logical and analytical thinking. It provides an efficient way to build mental discipline in understanding various concepts of all other fields. History reveals a strong relation between the theories of Music and Mathematics. The great Mathematician Pythagoras(569-475BC), often 
referred to as "The father of numbers" as well as "Father of harmony" made first concrete argument for a fundamental link between mathematics and music. His discovery of the overtone series and analysis of the acoustics and ratios involved in music have served as the foundation of harmony in western music. In Leibnitz's view music is an amazing secret exercise of the soul in arithmetic without knowing it's act of counting. Indian classical music is as ancient as Indian History. The origin of Indian classical music has been acknowledged to be from Vedas. The Sama Veda which was believed to have laid foundation for Indian classical music consists of hymns from Rigveda which were chanted with sacred mantras in three different pitches in a systematic rhythmic way. The two main sub-genres of Indian music are Carnatic music (South Indian) and Hindustani music (North Indian). Here our emphasis is on Carnatic music. Indian Carnatic music was developed in a systematic manner during 15th and 16th centuries. Sri Purandara Dasa, known as "Father of Carnatic Music" formulated a methodical system which is widely being used in teaching of Carnatic Music. The important elements of Carnatic music are: Sruthi (Pitch), Swara (Note), Raga and Tala (Rhythm) which are been constructed and practiced in a more systematic way than in any other Music systems. The 7 major notes "Sa-Ri-Ga-Ma-Pa-Da-Ni" in Carnatic music with allotted numerical values to their variations: 0-Sa,1-Ri1,2-Ri2=Ga1,3-Ri3=Ga2,4-Ga3,5-Ma16-,Ma2,7-Pa,8-Da1,9-Da2=Ni1,10-Da3=Ni2,11-Ni3, form a cyclic group $Z_{12}=$ $\{0,1,2,3,4,5,6,7,8,9,10,11\}$. Melodies in Indian classical music are being produced by unique combination of pitches, which are called as Ragas. Each raga is a collection of pitches in a specific order using a particular formula defined for it. There are 72 Janaka ragas/Melakartha ragas, also known as parent ragas consisting of all seven swaras including the first swara 'Sa' of the next octave, whereas there are many janya ragas by omitting/adding few more swaras to the janaka ragas. The arrangement of all swaras in a Melakartha raga is according to the combinations of "Ri", "Ga", "Ma", "Da" and "Ni". These 72 are broadly divided into 12 chakras with each 6 ragas, and 2 groups one with 36SuddhaMadhyamam(Ma1) and 36PrathiMadhyamam(Ma2).The 36 of each group are with the combinations of $\mathrm{Ri}, \mathrm{Ga}, \mathrm{Da}$, Ni with 3 variations in each by avoiding the over laps of Ri3-Ga1, Da3-Ni1. The "Ka-Ta-Pa-Ya" scheme which was used by ancient Indian Mathematicians for different purposes is also used to find the Melakartha number of a Janaka raaga. In this scheme consonants of Sanskrit are allotted with numerals 1 to 9, 0 and a Melakartha raga number is determined by decoding the first two letters from the name of the raga. There is a Mathematical algorithm to determine the swaras from a Melakartha number $\mathrm{k}$. For $\mathrm{k}<=36$, the melakartha raga comes under Sudha madhyama M1 ragaas whereas for $\mathrm{k}>36$ it will be a prathimadhyama raaga. The remaining sets of swaras $\mathrm{Ri}, \mathrm{Ga}$ (Purvangaswaras) and $\mathrm{Da}$, $\mathrm{Ni}$ (Uttarangaswaras) are determined by the quotient and remainder when k-1/k-36-1 is divided by 6 . Taala is a cyclical metre consisting of beats to measure musical time. The three basic units of a Taala cycle are Laghu, Dhrutha and Anudhrutha. Dhrutha has 2 beat counts; Anudhrutha has 1 beat count whereas number of beat counts for Laghu is not fixed. The Indian Carnatic music system consists of 7 major Taalas: Dhruva, Matya, Rupaka, Jhampa, Triputa, Ata, Eka and each of these Taala has a formula to define the units of Taala that a particular Taala should contain. These 7 Taalas has 2 more classifications: Jaathi and Gathi.Jaathi defines number of beat counts in Laghu. There are 5 Jaathis and 5 Gathis: Tisra (3), Chathurasra (4) Khanda (5), Misra (7) and Sankeerna (9). Gathi defines number of sub beats for each beat count for all 3 units Laghu, Dhrutha and Anudhrutha of one cycle of a Taala. These 7 Taalas with 5 of each Jathi and Gatis define 7X5X5=175 Taalas.

There have been some studies to analyse the impact of learning music in improvising mathematical skills in students. Holmes and Hallam ${ }^{(1)}$, conducted a Quasi-experimental design for children aged 4 to 7 who were made into two groups one with musical training the other as controlled groups. The findings of this study provided evidence to significantenhancement in learning Mathematics among the children of the trained groups. Chao-Fernández et al. ${ }^{(2)}$ also experimented with 50 students from different primary schools who were made in to two groups: Controlled group (CG) and Experimental group (EG). They analyzed the influence of musical activities in improvising Mathematical abilities and observed significant differences in the pre-test and the post- test abilities. An et al. ${ }^{(3)}$ presented in their article an exploratory investigation to observe the positive effects of Math-Music interdisciplinary teaching to improvise the multiple mathematical abilities. Ribeiro and Santos ${ }^{(4)}$ assessed two groups of primary school children one with developmental dyscalculiaanother with typically developed, by providing a Musical training to improvise Mathematical skills. They used a double-blinded quasi experimental design to measure the impact of Musical training on numerical cognition abilities at four different stages of tests. They found Musical Training as a remedial measure in Children with Developmental Dyscalculia. Raja and Bhalla ${ }^{(5)}$ in her yearlong study assessed private school children by astandardised international psychometric test, the results showed statistically significant improvement in Mathematical ability with the intervention of Music for the students of experimental group to the students of controlled group. Gaab and $\mathrm{Zuk}^{(6)}$ mentioned his views on learning instrumental music to improvise the ability to understand the Mathematical concepts such as fractions and ratios. Balaji ${ }^{(7)}$ correlated the creative process that is involved in melodic improvisation of raagalaapana in Carnatic music with Mathematical proof writing activity. Sridhar et al. ${ }^{(8)}$ developed an algorithm to estimate the fundamental frequency which is essential in Carnatic music signal processing. Based on the biological mutation theory using the characteristics of Carnatic music, the fundamental frequency of nearly 100 songs was estimated against the singing range of famous classical singers. 
Most of these studies were based on western music to analyse the influence of Music training on learning mathematics during the school education. Some of those are on mathematics involved in Carnatic Music. The Indian Carnatic music has a systematic and methodical process of learning and performing. For many years learning music was an integral part of Indian educational system. There were not many studies to observe the analytical skills that are attained in learning mathematics and Carnatic music together which are common for both. Studying these mathematical characteristics of Carnatic musicians help in understanding the importance of mathematical skills need not only science related subjects but also to excel in fine arts.

\section{Methodology}

\subsection{Research Objectives}

This study aims first in identifying the aptitude of the Carnatic musicians towards Mathematics as a part of their academics. Then to identify the impact of learning Mathematics as well Music together on their analytical, logical and reasoning skills in both the fields.

\subsection{Hypotheses of the study}

The research hypotheses have been formulated, keeping in view the objectives of the study, which is, finding the association between different demographic factors in identifying the Sruthi, Rhythm and Mathematics related concepts.

\subsection{Research Methodology}

The present study is undertaken to study the effect of Mathematical skills in their analytical musical skills. This research highlights at what level of association with Mathematics is increasing the observational and logical skills in Carnatic Musicians. Empirical research method is adopted.

\subsubsection{Research Hypotheses}

The following research hypotheses have been formulated, keeping in view of the objectives of the study.

1. $\mathrm{H}_{11}$ : There is an association between opting Mathematics as part of academics and learning Carnatic music.

2. $\mathrm{H}_{12}$ : There is an association between demographic factors and identification of Sruthi, Rhythm of Carnatic music.

3. $\mathrm{H}_{13}$ : The attributes, association with Mathematics, identification of Sruthi, Rhythm and logical reasoning.

\subsection{Data Collection \& Methodology}

The research is conducted on a sample of 153 respondents which is collected through a structured questionnaire using Microsoft forms on the basis of random sampling method. The data have been analysed and hypotheses have been tested by using valid statistical tools that is descriptive statistics, chi square test using IBM SPSS version 25. Based on the resulting output, the data and results have been interpreted.

\section{Data Analysis}

\subsection{Demographic Factors}

A glance at the information on the demographic factors [Table 1] reveals that out of a total sample of 153 musicians, about age, the distribution of musicians is relatively same, that is the younger age group with $34 \%$ in the age group $18-25$ years, $20 \%$ are belong to $26-35$ years, $24 \%$ is from $36-45$ years and the group above 45 is $22 \%$. It is observed that majority of the respondents $35 \%$ are graduates, $50 \%$ are postgraduates and $10 \%$ are higher than postgraduates. An investigation of the mathematics association of respondents shows that $24 \%$ are High School and $46 \%$ are under graduates. We can also observe that there are most of the respondents in the Association with Indian Carnatic Music, 38\% are Learner and Performer (Vocal) and 18\% are listeners. The data on the trained in music indicates that, majority of the respondents had training of more than 10 years. 
Table 1. Frequency distribution and Demographic Factors

\begin{tabular}{|c|c|c|c|c|}
\hline S.No & Variable & Category & Frequency & Percentage \\
\hline \multirow{4}{*}{1} & \multirow{4}{*}{ Age } & $18-25$ & 52 & 34 \\
\hline & & $26-35$ & 31 & 20 \\
\hline & & $36-45$ & 36 & 24 \\
\hline & & above 45 & 34 & 22 \\
\hline \multirow{5}{*}{2} & \multirow{5}{*}{ Education } & High School & 4 & 3 \\
\hline & & Intermediate & 3 & 2 \\
\hline & & Under Graduate & 54 & 35 \\
\hline & & Post Graduate & 76 & 50 \\
\hline & & Higher than Post Graduate & 16 & 10 \\
\hline \multirow{5}{*}{3} & \multirow{5}{*}{$\begin{array}{l}\text { Association with } \\
\text { Mathematics }\end{array}$} & High School & 37 & 24 \\
\hline & & Intermediate & 24 & 16 \\
\hline & & Under Graduate & 70 & 46 \\
\hline & & Post Graduate & 20 & 13 \\
\hline & & Higher than Post Graduate & 2 & 1 \\
\hline \multirow{7}{*}{4} & \multirow{7}{*}{$\begin{array}{l}\text { Association with Indian } \\
\text { Carnatic Music }\end{array}$} & Listener & 27 & 18 \\
\hline & & Learner and Performer (Vocal) & 58 & 38 \\
\hline & & Learner and Performer (Instrument) & 18 & 12 \\
\hline & & Teacher and Performer (Vocal) & 17 & 11 \\
\hline & & Teacher and Performer (Instrument) & 20 & 13 \\
\hline & & Performer (Vocal) & 9 & 6 \\
\hline & & Performer (Instrument) & 4 & 3 \\
\hline \multirow{7}{*}{5} & \multirow{7}{*}{ No. Of years trained } & $0-4$ & 26 & 17 \\
\hline & & $5 \_9$ & 23 & 15 \\
\hline & & $10 \_14$ & 34 & 22 \\
\hline & & $15-19$ & 18 & 12 \\
\hline & & $20-24$ & 26 & 17 \\
\hline & & $25-29$ & 8 & 5 \\
\hline & & $>30$ & 18 & 12 \\
\hline
\end{tabular}

From [Figure 1] it can be observed that a nearly half of the Carnatic Musicians had their inclination towards learning Mathematics up to their Under-graduate level.

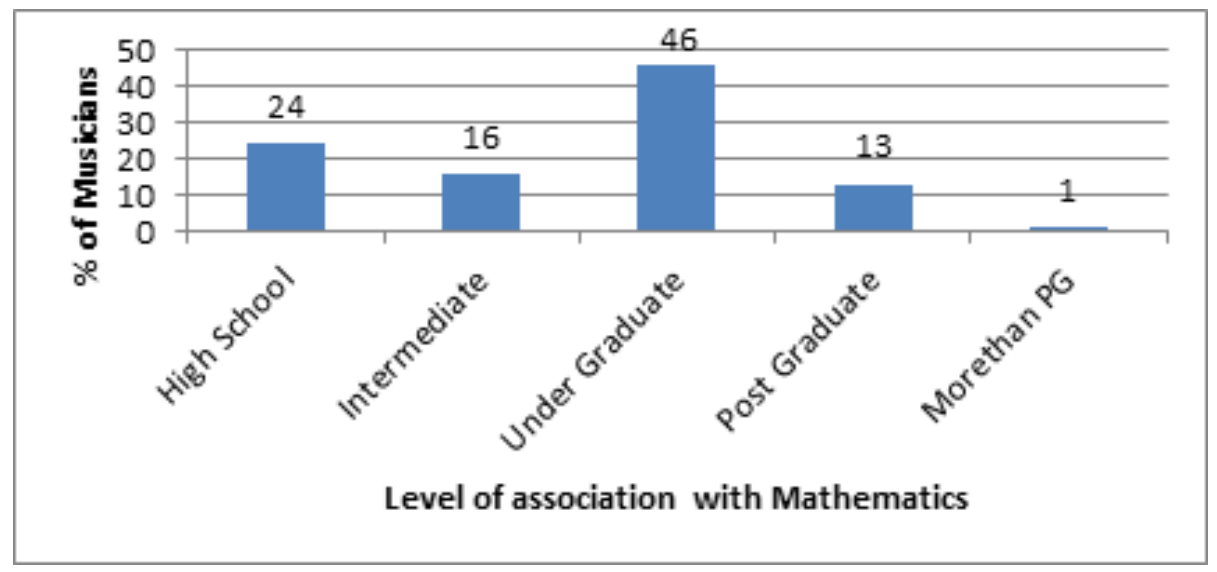

Fig 1. Association with Mathematics of Carnatic Musicians 
From [Figure 2] we observe that "Identifying variations in Sruthi" (Audio-1) needs more observational and analytical skills as the percentage of correctly answered is increasing accordingly with the number of years of association with Mathematics. Hence it is directly proportional to association with Mathematics.

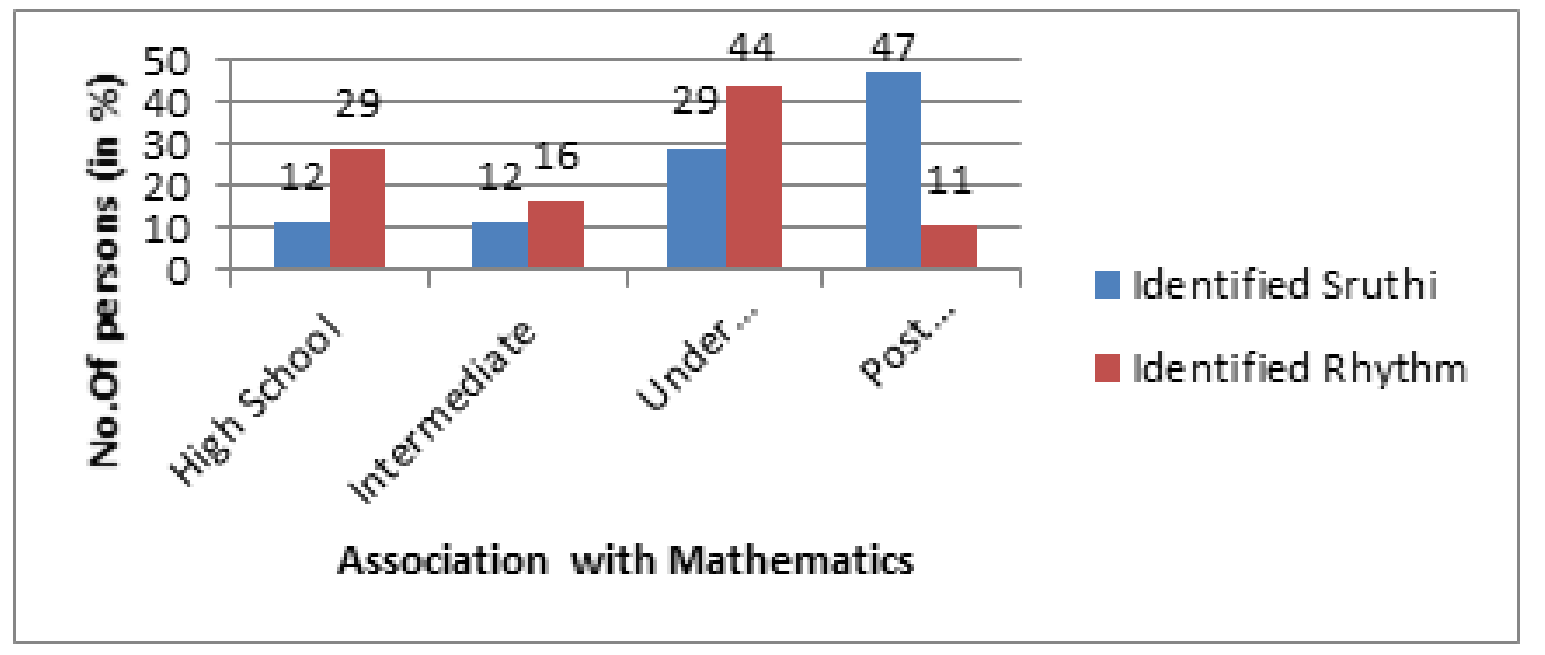

Fig 2. Impact of "Association with Mathematics" on answering Sruthi and Rhythm

From [Figure 3] we observe that the analytical, observational, and logical skills in identifying not only in Mathematics but also in Carnatic music concepts such as Sruthi and Rhythm are closely related to their association with Mathematics.

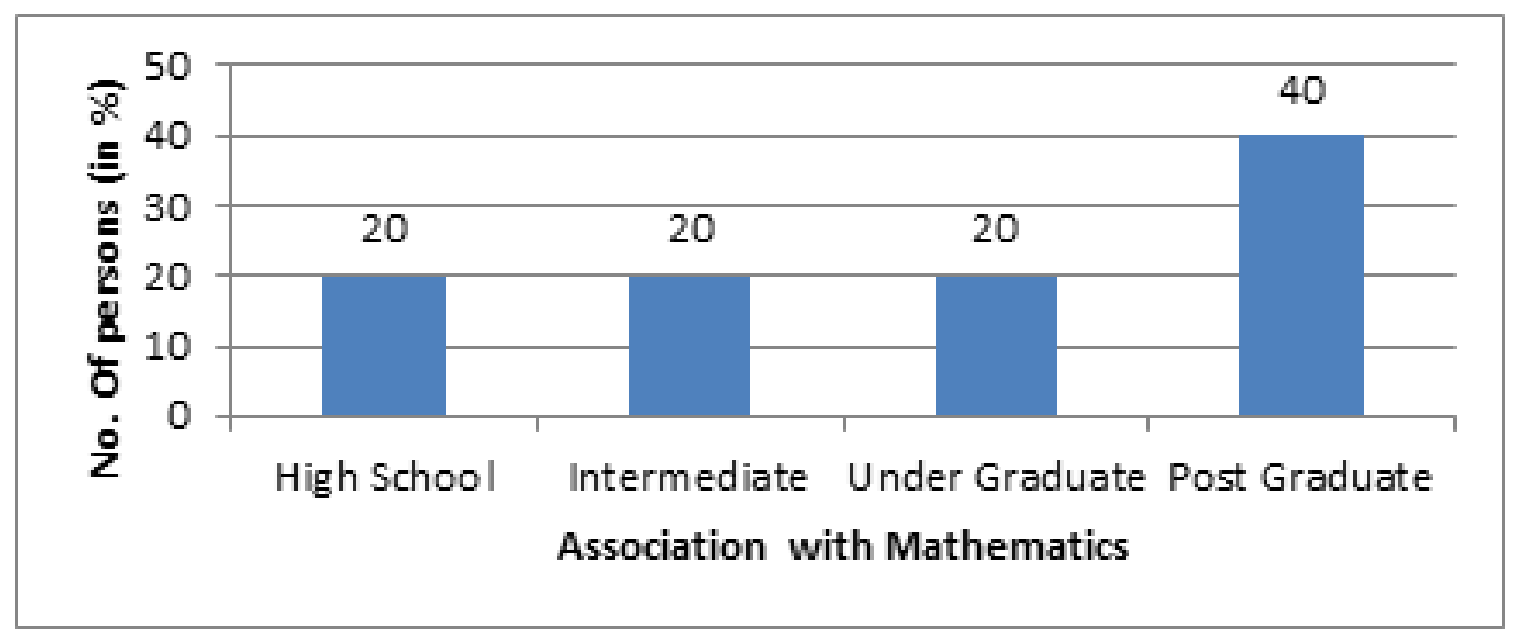

Fig 3. Impact of "Association with Mathematics" on answering Math and Music related concepts

\subsection{Testing of Hypotheses}

The hypotheses $\mathrm{H}_{11}, \mathrm{H}_{12}, \mathrm{H}_{13}$ are taken for the study and have been tested using Chi-square test for independence of attributes. From [Table 2] it is observed that $\mathrm{p}$ - value is greater than 0.05 for attributes Age, Education, Association with mathematics, no. of years of training which implies that there is no association between various demographic factors and identification of Sruthi and Rhythm and logical reasoning of mathematics questions. From this we can also observe that, there is an association between education and solving the mathematical questions, association of mathematics and identification of Sruthi and Rhythm. 
Table 2. Chi-square test for various attributes and identification of Sruthi and Rhythm, ability to solve Mathematical questions

\begin{tabular}{|c|c|c|c|}
\hline & Variable & $\mathrm{p}$ - Value & Interpretation \\
\hline \multirow{5}{*}{ Age } & Sruthi & 0.924 & \multirow{5}{*}{$\begin{array}{l}\text { There is no association between age and Sruthi and Rhythm } \\
\text { recognition; Age and Math ability }\end{array}$} \\
\hline & Rhythm & 0.725 & \\
\hline & Analytical & 0.583 & \\
\hline & Numerical & 0.117 & \\
\hline & Logical & 0.386 & \\
\hline \multirow{5}{*}{ Education } & Audio 1 & 0.406 & \multirow{5}{*}{$\begin{array}{l}\text { There is no association between Education and Sruthi and Rhythm } \\
\text { recognition; but an association between Education and Math ability }\end{array}$} \\
\hline & Audio 2 & 0.53 & \\
\hline & Analytical & 0.155 & \\
\hline & Numerical & 0.003 & \\
\hline & Logical & 0.044 & \\
\hline \multirow{7}{*}{ Maths association } & $\begin{array}{l}\text { Association with Car- } \\
\text { natic music }\end{array}$ & 0.419 & There is no association between Math association and Carnatic music \\
\hline & Trained & 0.698 & There is no association between Math association and trained in music \\
\hline & Sruthi & 0.001 & There is an association between Education and Sruthi recognition \\
\hline & Rhythm & 0.664 & \multirow{2}{*}{$\begin{array}{l}\text { There is no association between Education and Rhythm recognition; } \\
\text { Education and analytical ability }\end{array}$} \\
\hline & Analytical & 0.563 & \\
\hline & Numerical & 0.048 & There is an association between Education and numerical ability \\
\hline & Logical & 0.457 & There is no association between Education and logical ability \\
\hline \multirow{5}{*}{ Trained } & Sruthi & 0.998 & \multirow{5}{*}{$\begin{array}{l}\text { There is no association between trained and Sruthi and Rhythm } \\
\text { recognition; age and Math ability }\end{array}$} \\
\hline & Rhythm & 0.931 & \\
\hline & Analytical & 0.191 & \\
\hline & Numerical & 0.172 & \\
\hline & Logical & 0.744 & \\
\hline \multirow{3}{*}{ Audio 1} & Analytical & 0.347 & \multirow{3}{*}{ There is no association between Sruthi recognition and Math ability } \\
\hline & Numerical & 0.191 & \\
\hline & Logical & 0.535 & \\
\hline \multirow{3}{*}{ Audio 2} & Analytical & 0.176 & \multirow{3}{*}{ There is no association between Rhythm recognition and Math ability } \\
\hline & Numerical & 0.771 & \\
\hline & Logical & 0.834 & \\
\hline
\end{tabular}

\section{Conclusion}

Our Ancient Indian educational system of "Gurukula" provided each individual holistic and integrated education which was included with learning of all subjects as "Sastras". As the generations are passing through, we are arriving to the practice of learning different subjects in disjoint cubical. Acquiring Mathematical skills is an integral part of one's individual learning. Being good in any one or few of the Art forms enhances overall development. In general Mathematics is considered as a subject that supports Scientific and Technical skills which involve the functioning of the left side of the brain. And Music is taken granted as an art form that is involved with aesthetic sense and emotions which involve the functioning of the right side of the brain. But certain cognitive and reasoning skills are common in learning Mathematics and Music. Studying these Mathematical characteristics of Carnatic Musicians may help in understanding the importance of Mathematical skills needed not only Science related subjects but also to excel in fine arts.

In this study it is observed that a considerable count of the Carnatic Musicians are having Mathematics as one of their subjects up to their Under graduate studies. Learning them both can complement each other's enhancement. By choice or chance some may not opt to continue Mathematics in their higher education, but their aptitude towards Mathematics will certainly enhance the ability to understand the key concepts in Carnatic music. 


\section{Limitations and Suggestions}

This study is conducted for a small sample size with 153 Carnatic Musicians scattered in different places of India and few places outside India. There was difficulty in reaching larger number of Musicians and to convince them to be a part of this study. This type of study can be extended to larger groups, added with more parameters so as to observe more interesting and important outcomes.

\section{References}

1) Holmes S, Hallam S. The impact of participation in music on learning mathematics. London Review of Education. 2017;15(3):425-438. Available from: https://doi.org/10.18546/LRE.15.3.07.

2) Chao-Fernández A, Mato-Vázquez D, Chao-Fernández R. Influence of Musical Learning in the Acquisition of Mathematical Skills in Primary School. Mathematics. 2003;8(11). Available from: https://doi.org/10.3390/math8112003.

3) An S, Capraro MM, Tillman DA. Elementary Teachers Integrate Music Activities into Regular Mathematics Lessons: Effects on Students' Mathematical Abilities. Journal for Learning through the Arts. 2013;9(1). Available from: https://dx.doi.org/10.21977/d99112867.

4) Ribeiro FS, Santos FH. Persistent effects of musical training on mathematical skills of children with developmental dyscalculia. Frontiers in psychology. 2020;10(2888). Available from: https://doi.org/10.3389/fpsyg.2019.02888.

5) Raja V, Bhalla DO. Impact of Carnatic music training on the mathematical ability of children. Early Child Development and Care. 2020;15(1). Available from: https://doi.org/10.1080/03004430.2020.1832484.

6) Gaab N, Zuk J. Is There a Link between Music and Math? Scientific American Mind. 2017. Available from: https://www.scientificamerican.com/article/isthere-a-link-between-music-and-math/.

7) Balaji S. Exploring Raaga Improvisations of Carnatic Music with Mathematical Proof Writing. InBridges 2019 Conference Proceedings. $2019 ;$;. 403-406. Available from: https://archive.bridgesmathart.org/2019/bridges2019-403.pdf.

8) Sridhar R, Karthiga S, Geetha TV. Fundamental frequency estimation of carnatic music songs based on the principle of mutation. International Journal of Computer Science Issues. 2010;7(4). Available from: https://Math\&Music/mATH\%20\&MUSIC.pdf. 